\title{
Review of nut phytochemicals, fat-soluble bioactives, antioxidant components and health effects ${ }^{2 / 3}$
}

\author{
Cesarettin Alasalvar ${ }^{1 *}$ and Bradley W. Bolling ${ }^{2}$ \\ ${ }^{1}$ TÜBİTAK Marmara Research Centre, Food Institute, PO Box 21, 41470 Gebze, Kocaeli, Turkey \\ ${ }^{2}$ Department of Food Science, University of Wisconsin-Madison, 1605 Linden Dr., Madison, WI 53706, USA
}

(Submitted 17 June 2014 - Final revision received 8 September 2014 - Accepted 19 September 2014)

\section{Abstract}

The levels of phytochemicals (total phenols, proanthocyanidins, gallic acid + gallotannins, ellagic acid + ellagitannins, flavonoids, phenolic acids, stilbenes and phytates), fat-soluble bioactives (lipid, tocols, phytosterols, sphingolipids, carotenoids, chlorophylls and alkyl phenols) as well as natural antioxidants (nutrient and non-nutrient) present in commonly consumed twelve nuts (almond, Brazil nut, cashew, chestnut, hazelnut, heartnut, macadamia, peanut, pecan, pine nut, pistachio and walnut) are compared and reported. Recent studies adding new evidence for the health benefits of nuts are also discussed. Research findings from over 112 references, many of which have been published within last 10 years, have been compiled and reported.

\section{Key words: Nuts: Phytochemicals: Bioactives: Natural antioxidants: Antioxidant activity: Health effects}

Nuts contain a number of bioactives and health-promoting components $^{(1,2)}$. They are highly nutritious and contain macronutrients (fat, protein and carbohydrate) ${ }^{(3,4)}$, micronutrients (minerals and vitamins) ${ }^{(4)}$, fat-soluble bioactives (MUFA, PUFA, monoacylglycerols, diacylglycerols, TAG, phospholipids, sterol esters, tocopherols, tocotrienols, phytosterols, phytostanols, squalene, terpenoids, sphingolipids, carotenoids, chlorophylls, alkyl phenols, essential oils and among others $)^{(1,2,4-11)}$ and phytochemicals (phenolic acids such as hydroxybenzoic acid and hydroxycinnamic acid; flavonoids such as flavonols, flavones, flavanols or catechins, flavanones, anthocyanins, anthocyanidins and isoflavones; stilbenes; lignans; naphthoquinones; hydrolysable tannins (ellagitannins and gallotannins); condensed tannins or proanthocyanidins; ellagic acid; phenolic aldehydes; alkaloids; coumestan; phytates; terpenes; phytoestrogens and among others) ${ }^{(4,11-24)}$. Moreover, nuts contain numerous types of antioxidants with different properties ${ }^{(17,25)}$.

Nuts are recognised for their health-promoting aspects, particularly for their role in reducing CVD risk. This may be due to the favourable lipid profile and low-glycaemic nature of nuts ${ }^{(26,27)}$. Other evidence suggests that increased consumption of nuts increases antioxidant defences and reduces inflammation in populations with increased risk for $\operatorname{CVD}^{(28,29)}$. Furthermore, emerging observational and/or clinical studies suggest that increased consumption of nuts may reduce risk for cancer ${ }^{(30)}$, benefit cognitive function ${ }^{(31)}$, and reduce the risks of asthma ${ }^{(32,33)}$ and inflammatory bowel disease ${ }^{(34)}$, and among others.

The present review reported the levels of major phytochemicals, fat-soluble bioactives as well as natural antioxidants present in commonly consumed nuts. Recent studies adding new evidence for the health benefits of nuts are also discussed.

\section{Phytochemicals in nuts}

Nuts are rich in phenolic phytochemicals and are identified among the richest sources of dietary polyphenols ${ }^{(35)}$.

*Corresponding author: C. Alasalvar, email cesarettin.alasalvar@tubitak.gov.tr

Publication of these papers was supported by unrestricted educational grants from Federación Española de Sociedades de Nutrición, Alimentación y Dietética (FESNAD), International Nut and Dried Fruit Council (INC), International Union of Nutritional Sciences (IUNS), Fundación Iberoamericana de Nutrición (FINUT), Centro de Investigación Biomédica en Red de la Fisiopatología de la Obesidad y Nutrición (CIBERobn) and Centro Interuniversitario di Ricerca sulle Culture Alimentari Mediterranee (Ciiscam). The papers included in this supplement were invited by the Guest Editors and have undergone the standard journal formal review process. They may be cited. The Guest Editors declare that Salas-Salvadó is a nonpaid member of the World Forum for Nutrition Research and Dissemination of the International Nut and Dried Fruit Council. Angel Gil is President of the Fundación Iberomericana de Nutrición, which is a non-paid honorary position. Lluis Serra-Majem is the President of the Scientific Committee of the Mediterranean Diet Foundation and Scientific Director of the CIISCAM (Centro Interuniversitario di Ricerca sulle Culture Alimentari Mediterranee), Universita La Sapienza di Roma which are both non-paid, honorary positions. Goretti Guasch is the Executive Director and Member of the Executive Committee of the International Nut and Dried Fruit Council, which is a paid position. Mònica Bulló declares no conflict of interest. 
Table 1. Reported phytochemicals in nuts $(\mathrm{mg} / 100 \mathrm{~g})$

\begin{tabular}{|c|c|c|c|c|c|c|c|c|}
\hline Nut & Total phenols* $^{*}$ & Proanthocyanidins & Gallic acid + gallotannins & Ellagic acid + ellagitannins & Flavonoids† & Phenolic acids & Stilbenes & Phytates: \\
\hline Almond & $47-418$ & $176^{*}$ & $14-41 \S$ & $49-63 \S$ & 11 & $0.2-0.7 \|$ & $0.008-0.019$ & 350 \\
\hline Brazil nut & $112-310$ & $+\ddagger$ & $8 \cdot 3^{\star \star}$ & ND & ND & $11 \|$ & ND & 190 \\
\hline Cashew & $137-274$ & $2^{*}$ & $22 † \dagger$ & ND & 2 & ND & ND & 290 \\
\hline Chestnut & $1580-3673$ & $+\ddagger$ & $276-907^{*}$ & 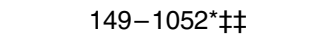 & 0.02 & $4-142^{\S \S}$ & ND & ND \\
\hline Hazelnut & $291-835$ & $491^{*}$ & $0 \cdot 2-4 \cdot 3^{|||| \mid}$ & ND & 12 & $2 \|$ & ND & 230 \\
\hline Heartnut & $148-248^{119}$ & ND & ND & $9-24^{\pi ा \pi}$ & ND & $34-62^{11 \pi}$ & ND & ND \\
\hline Macadamia & $46-156$ & $+\ddagger$ & ND & ND & ND & $4 \|$ & ND & 150 \\
\hline Peanut & $0.1-420$ & $11^{*}$ & ND & ND & 1 & $3-6 \|$ & $0.005-0.08^{*}$ & 170 \\
\hline Pecan & $1284-2016$ & $477^{*}$ & $22^{\star \star \star}$ & 301㧊 & 34 & $6-10^{\star \star \star}$ & ND & 180 \\
\hline Pine nut & $32-68$ & $+\ddagger$ & ND & ND & 0.5 & ND & ND & 200 \\
\hline Pistachio & $867-1657$ & $226^{*}$ & $1-2 \dagger+\dagger$ & ND & 16 & $1 \|$ & $0.009-0.16^{*}$ & 290 \\
\hline Walnut & $1558-1625$ & $60^{*}$ & $0.1^{f \neq \neq}$ & $6-823^{*}$ & $3-65^{\star} \dagger$ & $36^{*}$ & ND & 200 \\
\hline
\end{tabular}

ND, not detected.

*Data are expressed as $\mathrm{mg}$ of gallic acid equivalents $/ 100 \mathrm{~g}$ and obtained from Rothwell et $a l^{(104)}$, except heartnut.

†Data are obtained from USDA ${ }^{(105)}$, except walnut that is obtained from Rothwell et al. ${ }^{(104)}$ and USDA ${ }^{(105)}$.

$\ddagger$ Detected, but by qualitative method or not quantified on whole nut basis. Data are obtained from Venkatachalam \& Sathe ${ }^{(3)}$.

$\S$ Data are obtained from Xie et al.

| Data are obtained from Bolling et al. ${ }^{(11)}$

If Data are obtained from Xie \& Bolling ${ }^{(45)}$

${ }^{* *}$ Data are obtained from John \& Shahidi ${ }^{(42)}$ and on a defatted kernel basis.

†† Data are obtained from Chandrasekara \& Shahidi ${ }^{(41)}$ and on a defatted kernel basis.

¥¥Data are obtained from Abe et al. ${ }^{(92)}$

§ Data are obtained from Otles \& Selek ${ }^{(106)}$

III Data are obtained from Pelvan et al.

II Data are expressed as $\mathrm{mg}$ of gallic acid equivalents $/ 100 \mathrm{~g}$ and obtained from Li et al. ${ }^{(108)}$.

${ }^{* *}$ Data are obtained from de la Rosa et al.

†† Data are obtained from Mandalari et al. ${ }^{(110)}$. 
<smiles>O=c1oc2c(O)c(O)cc3c(=O)oc4c(O)c(O)cc1c4c23</smiles>

Ellagic acid<smiles>O=P(O)(O)OC1C(OP(=O)(O)O)C(OP(=O)(O)O)C(OP(=O)(O)O)C(OP(=O)(O)O)C1OP(=O)(O)O</smiles>

Phytate<smiles>Oc1cc(O)c2c(c1)O[C@]1(c3ccc(O)c(O)c3)c3c(O)cc(O)cc3Oc3cc(O)c4c(c3OC21)OC(c1ccc(O)c(O)c1)[C@H](O)C4</smiles>

Proanthocyanidin A1<smiles>Oc1cc(O)c2c(c1)O[C@H](c1ccc(O)c(O)c1)[C@H](O)C2c1c(O)cc(O)c2c1O[C@H](c1ccc(O)c(O)c1)[C@H](O)C2</smiles>

Procyanidin B2<smiles>O=C(O)c1cc(O)c(O)c(O)c1</smiles>

Gallic acid<smiles>O=C(O)/C=C/c1ccc(O)cc1</smiles>

p-Coumaric acid<smiles>O=c1c(O)c(-c2ccc(O)c(O)c2)oc2cc(O)cc(O)c12</smiles>

Quercetin
$\mathrm{HO}$<smiles>Cc1cc(O)c2c(=O)c(-c3ccc(O)cc3)coc2c1</smiles>

Genistein<smiles>Oc1ccc(/C=C/c2cc(O)cc(O)c2)cc1</smiles>

Resveratrol<smiles>COc1cc(C[C@H](CO)[C@H](CO)Cc2ccc(O)c(OC)c2)ccc1O</smiles>

Secoisolariciresinol<smiles>Oc1cc(O)c2c(c1)O[C@H](c1ccc(O)c(O)c1)C(O)C2</smiles>

(+)-Catechin<smiles>O=C(OC1OC(=O)c2cc(O)c(O)c(O)c2-c2c1cc(O)c(O)c2O)c1cc(O)c(Oc2c(C(=O)O)cc(O)c(O)c2O)c(C(=O)OCC2OC(=O)c3cc(O)c(O)c(O)c3-c3cc(c(O)c(O)c3O)OC2=O)c1O</smiles>

Glansrin A

Fig. 1. Structures of some phytochemicals present in nuts.

A recent comprehensive review on tree nut phytochemicals has been published by Bolling et al. ${ }^{(11)}$. Therefore, a detailed compositional comparison was not intended for this review. It should be noted that quantitative values for phytochemicals in nuts vary widely in some instances. Proanthocyanidins and hydrolysable tannins are generally the most abundantly found polyphenols in some nuts (Table 1). Nuts also have a significant phytate content as well as flavonoid, phenolic acid and stilbene polyphenol classes. Fig. 1 shows the chemical structures of some phytochemicals present in nuts.

\section{Total phenols}

Data from the Folin-Ciocalteu assay, a non-specific method to characterise the content of phenols, indicate that nuts have a significant phenolic content. Chestnut, pecan and pistachio have greater than $1 \mathrm{~g}$ gallic acid equivalents $/ 100 \mathrm{~g}$, while most 
nuts have $>0 \cdot 1 \mathrm{~g}$ gallic acid equivalents/100 $\mathrm{g}$ (Table 1). Thus, several nuts are among the top dietary sources of polyphenols $^{(35)}$. It should be noted that the Folin-Ciocalteu assay could be confounded with the differential contribution of individual flavonoid to total phenol values ${ }^{(36)}$.

\section{Proanthocyanidins}

Proanthocyanidins are the most abundantly found class of polyphenols in almond, hazelnut, pecan and pistachio (Table 1). Nut proanthocyanidins are predominantly B-type, although A-type proanthocyanidins have been found in almond, peanut and hazelnut ${ }^{(37)}$. Nut proanthocyanidins are highly polymerised, with mean degrees of polymerisations ranging from $2 \cdot 6$ to $10 \cdot 8^{(38)}$.

\section{Hydrolysable tannins}

The hydrolysable tannins consist of glucose-bound gallic acid (gallotannins) or hexahydroxydiphenic acid (ellagitannins), which release gallic acid and ellagic acid upon acid hydrolysis, respectively. Most studies have quantified gallic or ellagic acid following hydrolysis of a nut extract. Thus, tannin structures are not well characterised for most nuts. Further analysis of hydrolysable tannins characterised in the presence of glansreginins $\mathrm{A}$ and $\mathrm{B}$ and glansrins $\mathrm{A}-\mathrm{D}$ in walnut ${ }^{(39)}$. Most nuts likely have hydrolysable tannins, with almond, pecan and walnut having the highest contents. Gallic acid was also identified in extracts of hazelnut and was present at $22 \mathrm{mg} / 100 \mathrm{~g}$ of defatted cashew kernels ${ }^{(40,41)}$. Brazil nut has $5.2 \mathrm{mg}$ free and $8.2 \mathrm{mg}$ bound gallic acid/100 g of defatted whole Brazil nut ${ }^{(42)}$. By contrast, peanut does not appear to have a significant gallic acid or hydrolysable tannin content ${ }^{(43)}$.

\section{Flavonoids}

Pecan, walnut, hazelnut and pistachio are rich sources of flavonoids (Table 1). Almond contains catechins, as well as flavonols such as naringenin, quercetin and kaempferol, predominantly as glycosides or rutinosides ${ }^{(44)}$. Flavonoids such as hazelnut, pistachio and pecan are mainly sources of catechins and gallocatechins, and pistachio has additional flavanone and flavone polyphenols.

\section{Phenolic acids}

Walnut and Brazil nut have the highest phenolic acid content among nuts with 36 and $11 \mathrm{mg} / 100 \mathrm{~g}$, respectively, although this polyphenol class has not been well characterised in most nuts (Table 1). Peanut has p-coumaric acid and protocatechuic acid, with caffeic acid only in Spanish peanut ${ }^{(43)}$. When gallic acid (free or derived from hydrolysable tannins) is included with phenolic acids, chestnut, pecan and almond have a significant phenolic acid content ranging from 14 to $900 \mathrm{mg} / 100 \mathrm{~g}$ (Table 1).

\section{Stilbenes}

The presence of stilbenes has been reported in almond, peanut and pistachio. These nuts have comparable levels of stilbenes, presented in the $\mu \mathrm{g} / 100 \mathrm{~g}$ range. Almond contains resveratrol-3-O-glucoside, concentrated in the skin ${ }^{(45)}$. The variability of resveratrol content among 109 US peanut cultivars over 2 years was $0.003-0.026 \mathrm{mg} / 100 \mathrm{~g}_{\text {peanut }}{ }^{(46)}$.

\section{Free and bound phenolics}

Nuts contain solvent-extractable phenolics as well as nonextractable and covalently bound phenolics. Bound phenolics are associated with dietary fibre, lignins or other cell wall components. Nuts are composed of 3-13\% of dietary fibre, with almond and pistachio having the highest content ${ }^{(4)}$. Bound phenolics may contribute $10-60 \%$ of the total in vitro antioxidant capacity of nut extracts ${ }^{(47)}$. Notably, macadamia has the highest level of bound phenolics among nuts, but has proportionally lower extractable phenolics and flavonoids ${ }^{(48)}$. Almond contains $1-2 \mathrm{mg}$ of bound proanthocyanidins and approximately $8 \mathrm{mg}$ of bound phenolic acids per $100 \mathrm{~g}^{(49,50)}$. Few studies have characterised the nature and types of bound phenolics in nuts, and analysis is inherently complicated by the use of harsh acidic or alkaline conditions used in their extraction.

\section{Phytates}

Phytates have been found in most nuts. Phytates are composed of various inositol phosphates and range from inositol phosphate-1 to inositol phosphate- 6 in almond and hazelnut ${ }^{(51)}$. Nuts have similar phytate contents ranging from 150 to $290 \mathrm{mg} / 100 \mathrm{~g}^{(3)}$.

\section{Other classes}

Juglone, a naphthoquinone, has been reported to be present in significant quantity in walnut, which had $7-19 \mathrm{mg} / 100 \mathrm{~g}$ among ten cultivars ${ }^{(52)}$.

\section{Fat-soluble bioactives in nuts}

There has been an increasing interest in discussing the functional characteristics of nut oils as they seem to be an interesting source of bioactive constituents. Fig. 2 shows chemical structures of some fat-soluble bioactives present in nuts. Table 2 summarises the fat-soluble bioactives in nuts (lipid, tocols, phytosterols, sphingolipids, carotenoids, chlorophylls and alkyl phenols).

\section{Lipid}

The oil content of nuts ranges from $2 \cdot 26 \%$ for European chestnut to $75.77 \%$ for macadamia ${ }^{(4)}$. The benefits of including nuts in human diet are partly related to their fat components. MUFA is the predominant fat-soluble bioactive in most nut oils, except Brazil nut, European chestnut, heartnut, pine nut and walnut that are rich in PUFA ${ }^{(10)}$. 
<smiles>CC1=CC(O)CC(C)(C)C1/C=C/C(C)=C/C=C/C(C)=C/C=C/C=C(C)/C=C/C=C(C)/C=C/C1=C(C)CC(O)CC1(C)C</smiles><smiles>CC1=CCCC(C)(C)C1/C=C/C(C)=C/C=C/C(C)=C/C=C/C=C(C)/C=C/C=C(C)/C=C/C1=C(C)CCCC1(C)C</smiles>

$\beta$-Carotene
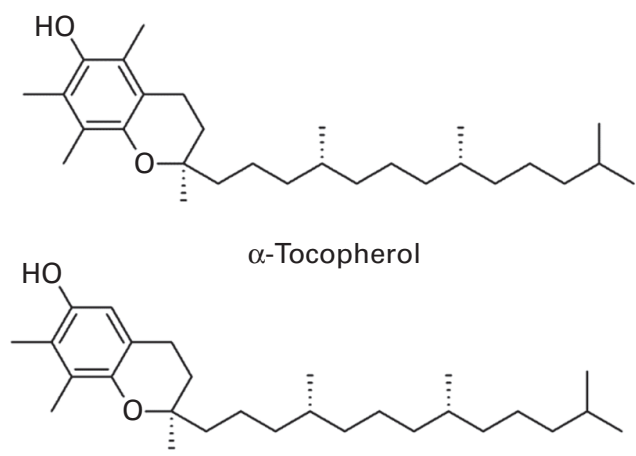

$\mathrm{HO}$<smiles>CC[C@H](CC[C@@H](C)[C@H]1CC[C@H]2[C@@H]3CC=C4CCCC[C@H]4[C@@H]3CC[C@]21C)C(C)C</smiles>

$\beta$-Sitosterol

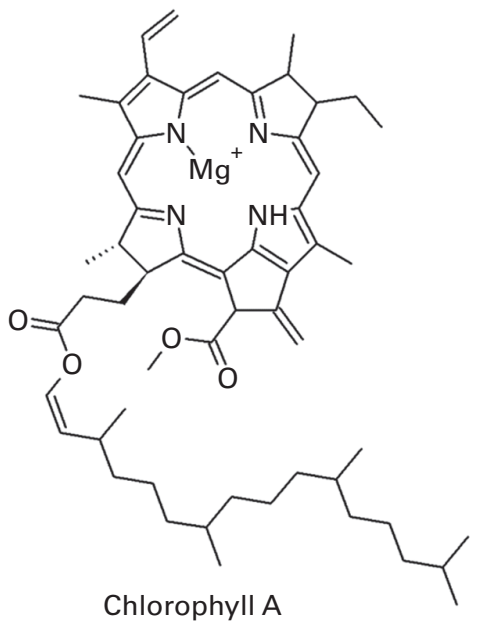

$\gamma$-Tocopherol<smiles>CCCCCCCCCC/C=C/CC/C=C/C(O)[C@@H](CO)NC(=O)CCCCCCCCCCCCCCCC</smiles>

$\mathrm{HO}$

$\mathrm{HO}$<smiles>CC[C@H]1OCC(C)CC1O</smiles>

D18:2-C16:0h-Glu

cerebroside

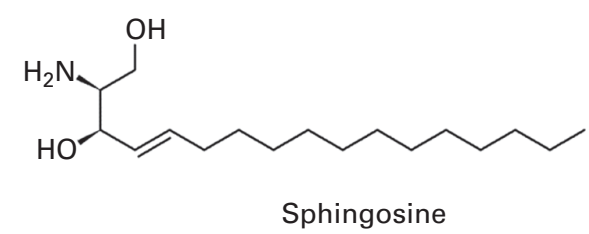

Fig. 2. Structures of some fat-soluble bioactives present in nuts.

\section{Tocols}

The mean content of total tocols range from $6 \cdot 15 \mathrm{mg} / 100 \mathrm{~g}$ for macadamia oil to $59.60 \mathrm{mg} / 100 \mathrm{~g}$ for chestnut oil (Table 2$)^{(10)}$. Oils extracted from various nuts have been reported to show significant tocol (tocopherols and tocotrienols) differences and patterns ${ }^{(1,4,5,9,53-61)}$. Data for tocol levels and patterns in twelve nuts (almond, Brazil nut, cashew, chestnut, heartnut, hazelnut, macadamia, peanut, pecan, pine nut, pistachio and walnut) have been reported elsewhere ${ }^{(10)}$. Vitamin E, consisting of $\alpha$-, $\beta$-, $\gamma$ - and $\delta$-tocopherols as well as tocotrienols, is a fat-soluble vitamin that generally functions as a potent antioxidant activity via chain-breaking reactions during peroxidation of unsaturated lipids ${ }^{(62)}$. It is considered to be a significant health-promoting component of nuts and affords health benefits to those who routinely consume nuts ${ }^{(63)}$. Compared with other nut oils, hazelnut oil has been reported to serve as an excellent source of vitamin $\mathrm{E}^{(53)}$, followed by pistachio, almond, pine nut ${ }^{(1)}$ and peanut ${ }^{(56)}$, respectively. Vitamin $\mathrm{E}$ content in nut oils range from 1.13 to $41.92 \mathrm{mg} / 100 \mathrm{~g}$, being lowest in European chestnut and highest in hazelnut ${ }^{(10)}$.

\section{Phytosterols}

Phytosterols, which are lipophilic plant-synthesised steroids, are one of the important bioactive classes of constitutes 
Table 2. Reported fat-soluble bioactives in nut oils $(\mathrm{mg} / 100 \mathrm{~g})$

\begin{tabular}{|c|c|c|c|c|c|c|c|}
\hline Nut & Lipid $(\%)^{*}$ & Tocolst & Phytosterols $\ddagger$ & Sphingolipids§ & Carotenoids & Chlorophylls & Alkyl phenols \\
\hline Almond & 49.93 & 28.60 & 271 & 240 & ND & ND & ND \\
\hline Brazil nut & 66.43 & $20 \cdot 15$ & 208 & 290 & ND & ND & ND \\
\hline Cashew & 43.85 & $7 \cdot 10$ & 199 & ND & $0.09 \|$ & ND & $146-2429$ \\
\hline Chestnut & $2 \cdot 26$ & 59.60 & 800 & ND & ND & ND & ND \\
\hline Hazelnut & $60 \cdot 75$ & 51.31 & 165 & 20 & ND & ND & ND \\
\hline Heartnut & 51.00 & $22 \cdot 50$ & ND & ND & ND & ND & ND \\
\hline Macadamia & $75 \cdot 77$ & $6 \cdot 15$ & 128 & ND & ND & ND & ND \\
\hline Peanut & 49.24 & 29.72 & 284 & ND & ND & ND & ND \\
\hline Pecan & 71.97 & 49.11 & 283 & 320 & $0.014^{\star *}$ & ND & ND \\
\hline Pine nut & 68.37 & $45 \cdot 80$ & 164 & 280 & ND & $0.007 \dagger \dagger$ & ND \\
\hline Pistachio & 45.39 & 39.77 & 184 & 330 & $6 \cdot 70 \neq \ddagger$ & $24.09^{\S \S}$ & $44^{\|\| \|}$ \\
\hline Walnut & $65 \cdot 21$ & 43.72 & 307 & 290 & ND & ND & ND \\
\hline
\end{tabular}

ND, not detected.

*Data are obtained from USDA ${ }^{(4)}$ (European chestnut and English walnut), except heartnut that is obtained from Li et al. ${ }^{(54)}$.

†Data are compiled from Alasalvar \& Pelvan ${ }^{(10)}$

$\ddagger$ Data are compiled from Alasalvar \& Pelvan ${ }^{(10)}$, except sweet chestnut that is obtained from Zlatanov et al. ${ }^{(112)}$.

$\S$ Data are obtained from Miraliakbari \& Shahidi ${ }^{(73)}$. The oils of nuts were extracted using chloroform/methanol.

$\|$ Data are mean value of $\beta$-carotene, lutein and zeaxanthin and obtained from Trox et al. ${ }^{(77)}$. Carotenoid content in cashew oil was calculated based on oil content of cashew $(43.85 \mathrm{~g} / 100 \mathrm{~g})$.

१ Data are obtained from Trevisan et al. ${ }^{(80)}$. The total amount of alkyl phenols in cashew oil was calculated based on oil content of cashew $(43.85 \mathrm{~g} / 100 \mathrm{~g})$.

** Data are mean value of lutein (27th week after flowering date) and obtained from Bouali et al. ${ }^{(78)}$.

t† Data are obtained from Cheikh-Rouhou et al. ${ }^{(79)}$.

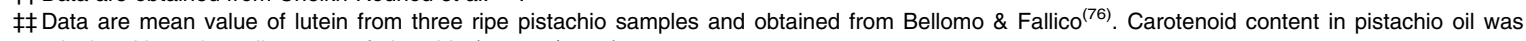
calculated based on oil content of pistachio $(45.39 \mathrm{~g} / 100 \mathrm{~g})$.

$\S \S$ Data are mean value of chlorophylls $b$ and $a$ from three ripe pistachio samples and obtained from Bellomo \& Fallico ${ }^{(76)}$. Chlorophyll content in pistachio oil was calculated based on oil content of pistachio $(45 \cdot 39 \mathrm{~g} / 100 \mathrm{~g})$.

|II Data are obtained from Saitta et al. ${ }^{(81)}$.

in nut oils. Phytosterol is a collective term, and saturated sterols are known as stanols. Sterols and stanols are differentiated by an alkane bond at the $\mathrm{C}_{1}$ position on the $\mathrm{B}$ ring. The total phytosterol content of nut oils expressed as $\mathrm{mg} / 100 \mathrm{~g}$ is given in Table 2 . Sweet chestnut oil contains the highest amount of total phytosterols $(800 \mathrm{mg} / 100 \mathrm{~g})$, followed by walnut $(307 \mathrm{mg} / 100 \mathrm{~g})$, peanut $(284 \mathrm{mg} / 100 \mathrm{~g})$, pecan $(283 \mathrm{mg} / 100 \mathrm{~g})$ and almond $(271 \mathrm{mg} / 100 \mathrm{~g})$. By contrast, macadamia oil contains the lowest total phytosterol content $(128 \mathrm{mg} / 100 \mathrm{~g})^{(10)}$. To the best of our knowledge, no phytosterol data on heartnut exist in the literature. Despite high level of phytosterols in chestnut oil, it may not be appreciable due to the presence of small amount of fat (0.81-2.26\%). Of the phytosterols, nuts are mainly composed of $\beta$-sitosterol but are also composed of a number of minor sterols, sterol esters and stanols ${ }^{(11)}$. Data on phytosterol levels and patterns in nuts (almond, Brazil nut, cashew, chestnut, heartnut, hazelnut, macadamia, peanut, pecan, pine nut, pistachio and walnut) have been reported elsewhere ${ }^{(1,2,4,5,9-11,53,56,60,64-71)}$.

\section{Sphingolipids}

Two recent reviews discussing the sphingolipid characteristics of certain nuts have been published ${ }^{(10,72)}$. Studies about sphingolipids in nuts are quite sparse. Miraliakbari \& Shahidi ${ }^{(73)}$ have measured sphingolipid levels in seven hexane- or chloroform-methanol extracted nut oils (almond, Brazil nut, hazelnut, pecan, pine nut, pistachio and walnut); values ranged from $20 \mathrm{mg} / 100 \mathrm{~g}$ (hazelnut oil) to $330 \mathrm{mg} / 100 \mathrm{~g}$ (pistachio oil) in chloroform-methanol extracted oils and are presented in Table 2 . The majority of the sphingolipid data have been derived by Miraliakbari \& Shahidi ${ }^{(1,73,74)}$, utilising a non-specific method of quantification. Thus, more effort is needed to gain reliable data on the sphingolipid content in nuts. Compared with other foods such as milk, egg, soyabeans, meat (chicken, beef and pork) and cereal (wheat), nuts have a comparatively low sphingolipid content.

\section{Carotenoids}

In contrast to other plant foods, certain nuts contain very low amounts of carotenoids such as $\alpha$ - and $\beta$-carotene, $\beta$-cryptoxanthin, lutein, lycopene and zeaxanthin ${ }^{(11,75-77)}$. Pistachio oil presents only traces of $\beta$-carotene and lutein $(<5 / 100 \mathrm{~g} \text { oil })^{(75)}$. Among twelve nuts (Table 2), only cashew oil $(0.09 \mathrm{mg} / 100 \mathrm{~g})$, pecan oil $(0.014 \mathrm{mg} / 100 \mathrm{~g})$ and pistachio oil $(6.70 \mathrm{mg} / 100 \mathrm{~g})$ have been reported to contain carotenoids $^{(76,77,78)}$. Trox et al. ${ }^{(77)}$ have reported that raw cashew contains traces of $\beta$-carotene, lutein and zeaxanthin. Bolling et $a l .{ }^{(11)}$ have mentioned that as most nuts are not significant dietary sources of carotenoids, an effort to improve carotenoid data may not be worthwhile.

\section{Chlorophylls}

The chlorophyll pigments are important quality parameters as they correlate with colour, which is a basic attribute for evaluating oil quality. Among commonly consumed nuts, only pine nut oil $(0.007 \mathrm{mg} / 100 \mathrm{~g})$ and pistachio oil $(24.09 \mathrm{mg} / 100 \mathrm{~g})$ have been reported to contain the lipid subclasses of chlorophylls ${ }^{(76,79)}$. In ripe pistachio samples, chlorophyll $a$ is approximately 3 -fold higher than chlorophyll 
$b$ counterpart $^{(76)}$. No other published information on the chlorophyll content of other nuts is available.

\section{Alkyl phenols}

Cashew oil contains $146-242 \mathrm{mg} / 100 \mathrm{~g}$ of anacardic acids and cardols $^{(80)}$, while pistachio oil has sixteen different cardanols $(44 \mathrm{mg} / 100 \mathrm{~g})^{(81)}$. To the best of our knowledge, alkyl phenols in other nuts have not been characterised and reported. A series of twelve components (anacardic acids, cardols, 2-methylcardols and cardanols) in cashew shell oil were isolated $^{(82)}$. Different levels and profiles of alkyl phenols in various cashew products (such as apple, nut, cashew nut shell liquid and fibre) have also been reported ${ }^{(80)}$

\section{Natural antioxidants in nuts}

Natural antioxidants present in nuts are in the form of nutrient and non-nutrient (phytochemicals) antioxidants. Every food plant including nuts contains numerous types of natural antioxidants with different properties. In addition to wellknown nutrient antioxidants (e.g. vitamins A, C and E and the mineral $\mathrm{Se}$ ), there are numerous non-nutrient antioxidants (e.g. carotenoids such as $\beta$-carotene and lycopene and phenolics) in food plants ${ }^{(24)}$.

Nuts are good sources of nutrient antioxidants (such as vitamin $\mathrm{E}$ and $\mathrm{Se})^{(4,24,83)}$. Among antioxidant vitamins (A, C and $\mathrm{E})$, vitamin $\mathrm{E}$ is the most abundantly found vitamin in most nuts. At suggested consumption level (1.5 oz or approximately $42.5 \mathrm{~g} / \mathrm{d})^{(84)}$, almond and hazelnut provide up to 74.8 and $72.7 \%$ vitamin E, respectively, of the daily $15 \mathrm{mg}$ recommended for adult males and females ${ }^{(24)}$. The other nuts contain much lower amount of vitamin E compared with almond and hazelnut. In general, nuts are not good sources of vitamins $\mathrm{A}$ and $\mathrm{C}$. With respect to Se, Brazil nut itself serves as an excellent source of this mineral compound. Only one kernel of Brazil nut (approximately $5 \mathrm{~g}$ ) supplies $174 \%$ of Se for $\mathrm{RDA}^{(24)}$.

With regard to non-nutrient antioxidants, several thousands of phytochemicals, some of which possess strong antioxidant activities (e.g. catechin, quercetin, tannins, ellagic acid, chlorogenic acid and cyanidin), have been reported ${ }^{(11,13,23,24,85-88)}$ Several studies have also reported that phenolic compounds possess much stronger antioxidant activities than nutrient antioxidants $^{(13)}$

Recently, Vinson \& Cai ${ }^{(89)}$ measured the levels of free and total polyphenols ( $\mu \mathrm{mol}$ catechin equivalents/g) in both raw and roasted nuts (almond, Brazil nut, cashew, macadamia, peanut, pecan, pistachio and walnut). Walnut had the highest levels of free and total polyphenols than in both the combined raw and roasted nut samples. Roasting had some effect on either free or total polyphenols in nuts and total polyphenols were slightly higher in roasted than in raw nuts. They also measured the efficacy of the antioxidants in the nuts. The order of decreasing the efficacy (increasing inhibitory concentration $50 \%\left(\mathrm{IC}_{50}\right)$ ) in raw nuts is walnut $>$ cashew $>$ hazelnut $>$ pecan $>$ almond $>$ macadamia $>$ pistachio $>$ Brazil nut $>$ peanut. Roasting causes a decline in efficacy. The total antioxidant activity of nuts has been assessed by different researchers using different assays (such as ferric-reducing ability of plasma, total oxyradical scavenging capacity, 2,2-diphenyl-1-picrylhydrazyl radical scavenging activity and 2,2-azino-bis (3-ethylbenz-thiazoline-6-sulfonic acid) radical scavenging activity); walnut possess the highest antioxidant activity in all assays among nuts ${ }^{(25,48,90-92)}$. In all nuts, most of the antioxidants are located in the skin (pellicle) and less than $10 \%$ is retained in the walnut when skin is removed ${ }^{(25)}$. In other words, the removal of skin from nuts reduces the antioxidant activity considerably ${ }^{(91)}$. When using an oxygen radical absorbance capacity assay of nuts, pecan has the highest total oxygen radical absorbance capacity value of $179 \cdot 40 \mu \mathrm{mol}$ of trolox equivalents $/ \mathrm{g}^{(17)}$, total phenolics $20 \cdot 16 \mathrm{mg}$ of gallic acid equivalents $/ \mathrm{g}^{(17)}$ and total flavonoids $34.01 \mathrm{mg} / 100 \mathrm{~g}^{(15)}$, whereas pistachio has the highest total isoflavone value of $176.9 \mu \mathrm{g} / 100 \mathrm{~g}$, lignans $198.9 \mu \mathrm{g} / 100 \mathrm{~g}$ and phytoestrogens $382.5 \mu \mathrm{g} / 100 \mathrm{~g}^{(19)}$. In addition, hazelnut contains the highest total content of proanthocyanidins or condensed tannins $(500 \cdot 7 \mathrm{mg} / 100 \mathrm{~g})^{(14,16)}$, among nuts.

Based on USDA available data, the total nut consumption (tree nuts and peanut) in the US is $162 \mathrm{mg} / \mathrm{d}$. In the European Union (EU), $5.0 \mathrm{~g}$ of peanut/d is consumed, contributing $71.5 \mathrm{mg}$ of polyphenols. Tree nuts have $86.9 \mathrm{mg}$ of polyphenols and thus nut contribution of polyphenols to the EU diet amounts to $158 \mathrm{mg} / \mathrm{d}$, which is very similar to that of the US diet ${ }^{(89)}$.

\section{Health benefits of nuts}

Traditionally, nuts have been used for improving immunity, digestion, wound healing and circulation, as well as analgesics $^{(93)}$. Today, nut consumption is recognised for its potential to reduce CVD risk. In $2003^{(84)}$ and $2004^{(94)}$, the US Food and Drug Administration granted a qualified health claim that consumption of $1.5 \mathrm{oz}$ (approximately $42.5 \mathrm{~g}$ )/d of most nuts, or specifically walnut, may reduce the risk of heart disease as part of a diet low in saturated fat and cholesterol. In 2011, European Food Safety Authority (EFSA) allowed an Article 13 claim that the consumption of $30 \mathrm{~g}$ of walnuts in the context of a balanced diet leads to improvement of endothelium-dependent vasodilation ${ }^{(95)}$. Claims can also be made for LDL-cholesterol reduction based on the MUFA/PUFA and linoleic/ $\alpha$-linoleic content of nuts ${ }^{(95)}$

Recent observational studies further support the association of increased nut consumption and reduced mortality. Data from the Nurses' Health Study and the Health Professionals Follow-up Study, two prospective cohort studies of 118962 adults with 24 and 30 years of follow-up, respectively, were used to examine the association between nut consumption and mortality ${ }^{(96)}$. Increasing frequency of nut consumption was associated with lower hazard ratios for death $(P<0.001)$ with 0.80 (95\% CI $0.73,0.86)$ for individuals consuming nuts seven or more times per week ${ }^{(96)}$. Rates of death from cancer, CVD, heart disease and respiratory disease were inversely related to frequency of nut consumption ${ }^{(96)}$. Observational data from the Australian Blue Mountains Eye Study also supported this finding. Higher frequency of nut consumption was associated with age- and sex-adjusted 
rates of inflammatory disease activity $(P=0 \cdot 02)$, but this trend is insignificant upon multivariable adjustment ${ }^{(97)}$.

Intervention studies have also provided new data suggesting health benefits of nut consumption. The Prevención con Dieta Mediterránea intervention study evaluated the effect of consuming nuts or olive oil with participants adhering to a Mediterranean diet, relative to a low-fat control diet ( $n 7447$ adults) ${ }^{(98)}$. Participants in the nuts group consumed $30 \mathrm{~g}$ of mixed walnut, hazelnut and almond per $d$. After a median follow-up of 4.8 years, both the Mediterranean diet with olive oil and nuts reduced the rates of cardiovascular events. The hazard ratio was 0.72 (95\% CI $0.54,0.96)$ for the nut-supplemented group compared with the control diet group ${ }^{(98)}$. The nut-supplemented group also had reduced risk of all-cause mortality. Those who consumed nuts more than three servings per week had the lowest rates of total mortality risk (HR $0.36,95 \%$ CI $0.22,0.66)^{(99)}$. Furthermore, cognitive improvement occurred in a subset of Prevención con Dieta Mediterránea participants at high vascular risk $(n \text { 522 })^{(31)}$. Assessments of cognitive function by the mini-mental state examination and clock drawing test were higher after 6.5 years of the intervention in both nuts and olive-oil supplemented groups ${ }^{(31)}$.

Other recent studies suggest that components in nuts beyond lipids contribute to mechanisms of cardioprotection. For example, apoE ${ }^{-/-}$mice fed a high-fat diet reduced atherosclerotic plaque development by $55 \%$, whereas walnut oil supplemented mice did not ${ }^{(100)}$. Also, acute consumption of walnut skins $(5.6 \mathrm{~g}$ ) for $3 \mathrm{~d}$ decreased the postprandial reactive hyperaemia index compared with baseline, in a crossover trial of $n 15$ healthy overweight and obese moderate hypercholesterolaemic adults ${ }^{(101)}$.

Further evidence supports the emerging role of nuts in reducing risk for insulin resistance and type 2 diabetes mellitus. Almond consumption $(56 \mathrm{~g} / \mathrm{d}$ for 4 weeks) by Chinese adults with type 2 diabetes mellitus with mild hyperlipidaemia decreased C-reactive protein, IL- 6 and TNF- $\alpha$ levels and increased resistance to $\mathrm{Cu}$-induced $\mathrm{LDL}$-oxidation relative to the control diet group ${ }^{(29)}$. Inclusion of $42.5 \mathrm{~g}$ of peanut butter in a carbohydrate-rich breakfast meal in a crossover study of $n 15$ women with high type 2 diabetes mellitus risk reduced postprandial glucose and enhanced gut satiety hormone secretion ${ }^{(27)}$. Nut polyphenols could also limit glycaemia by inhibiting carbohydrate digestion. Almond and chestnut tannins were identified as potent $\alpha$-amylase inhibitors and were confirmed to reduce blood glucose in rats fed maize (corn) $\operatorname{starch}^{(102,103)}$.

\section{Conclusions}

Nuts, which contain phytochemicals, fat-soluble bioactives, minor components as well as nutrient and non-nutrient antioxidants beyond their basic nutritional functions, offer an excellent choice for heart-healthy snack food and food additive. Nuts should be consumed with their skin (pellicles), whenever possible, because of their high phytochemical content as well as antioxidant activity. The present report provides a detailed and up to date summary and scientific review of the available data on nut antioxidant components and health.

\section{Acknowledgements}

The authors' contributions are as follows: C. A. contributed introduction, fat-soluble bioactives in nuts, natural antioxidants in nuts and conclusions; B. W. B. contributed introduction, phytochemicals in nuts, health benefits of nuts and conclusions.

All authors declare that there are no conflicts of interest.

\section{References}

1. Miraliakbari H \& Shahidi F (2008) Lipid class compositions, tocopherols and sterols of tree nut oils extracted with different solvents. J Food Lipids 15, 81-96.

2. Alasalvar C, Shahidi F, Amaral JS, et al. (2009) Compositional characteristics and health effects of hazelnut (Corylus avellana L.): an overview. In Tree Nuts: Composition, Phytochemicals, and Health Effects, pp. 185-214 [C Alasalvar and F Shahidi, editors]. Boca Raton, FL: CRC Press, Taylor \& Francis Group.

3. Venkatachalam M \& Sathe SK (2006) Chemical composition of selected edible nut seeds. I Agric Food Chem 54, 4705-4714

4. US Department of Agriculture (2013) USDA National Nutrition Database for Standard Reference, Release 26. Springfield, VA: USDA.

5. Maguire LS, O'Sullivan SM, Galvin K, et al. (2004) Fatty acid profile, tocopherol, squalane and phytosterol content of walnuts, almonds, peanuts, hazelnuts and the macadamia nut. Int J Food Sci Nutr 3, 171-178.

6. Phillips KM, Ruggio DM \& Ashraf-Khorassani M (2005) Phytosterol composition of nuts and seeds commonly consumed in the United States. J Agric Food Chem 53, 9436-9445.

7. Fang F, Ho C-T, Sang S, et al. (2005) Determination of sphingolipids in nuts and seeds by a single quadrupole liquid chromatography-mass spectrometry method. J Food Lipids 12, 327-343.

8. Shahidi F \& Miraliakbari H (2006) Tree nut oils and by products: compositional characteristics and nutraceutical applications. In Nutraceutical and Specialty Lipids and Their Co-products, pp. 159-168 [F Shahidi, editor]. Boca Raton, FL: CRC Press, Taylor \& Francis Group.

9. Ryan E, Galvin K, O'Connor TP, et al. (2006) Fatty acid profile, tocopherol, squalene and phytosterol content of Brazil, pecan, pine, pistachio and cashew nuts. Int J Food Sci Nutr 57, 219-228.

10. Alasalvar C \& Pelvan E (2011) Fat-soluble bioactives in nuts Eur J Lipid Technol 113, 943-949.

11. Bolling BW, Oliver Chen C-Y, McKay D, et al. (2011) Tree nut phytochemicals: composition, antioxidant capacity, bioactivity, impact factors: a systematic review of almonds, Brazils, cashews, hazelnuts, macadamias, pecans, pine nuts, pistachios and walnuts. Nutr Res Rev 24, 244-275.

12. Ghelardini C, Galeotti N, Lelli C, et al. (2001) M1 receptor activation is a requirement for arecoline analgesia. Farmaco 56, 383-385.

13. Shahidi F \& Naczk M (2004) Phenolics in Food and Nutraceuticals. Boca Raton, FL: CRC Press, Taylor \& Francis Group.

14. US Department of Agriculture (2004) Database for the proanthocyanidin content of selected foods. http://www. nal.usda.gov/fnic/foodcomp (accessed September 2006). 
15. US Department of Agriculture (2007) Database for the flavonoid content of selected foods, release 2.1. http:// www.ars.usda.gov/nutrientdata (accessed September 2007).

16. Gu L, Kelm MA, Hammerstone JF, et al. (2004) Concentrations of proanthocyanidins in common foods and estimations of normal consumption. J Nutr 134, 613-617.

17. Wu X, Beecher GR, Holden JM, et al. (2004) Lipophilic and hydrophilic antioxidant capacities of common foods in the United States. J Agric Food Chem 52, 4026-4037.

18. Wijeratne SSK, Abou-Zaid MM \& Shahidi F (2006) Antioxidant polyphenols in almond and its coproducts. J Agric Food Chem 54, 312-318.

19. Thompson LU, Boucher BA, Liu Z, et al. (2006) Phytoestrogen content of foods consumption in Canada, including isoflavones, lignans, and coumestan. Nutr Cancer 54, 184-201.

20. Oliver Chen C-Y \& Blumberg J (2008) Phytochemical composition of nuts. Asia Pac J Clin Nutr 17, 329-332.

21. Alasalvar C, Karamać M, Amarowicz R, et al. (2006) Antioxidant and antiradical activities in extracts of hazelnut kernel (Corylus avellana L.) and hazelnut green leafy cover. J Agric Food Chem 54, 4826-4832.

22. Alasalvar C, Hoffman AM \& Shahidi F (2009) Antioxidant activities and phytochemicals in hazelnut (Corylus avellana L.) and hazelnut by-products. In Tree Nuts: Composition, Phytochemicals, and Health Effects, pp. 215-235 [C Alasalvar and F Shahidi, editors]. Boca Raton, FL: CRC Press, Taylor \& Francis Group.

23. Alasalvar C, Karamać M, Kosińska A, et al. (2009) Antioxidant activity of hazelnut skin phenolics. J Agric Food Chem 57, 4645-4650.

24. Alasalvar C \& Shahidi F (2009) Natural antioxidants in tree nuts. Eur J Lipid Technol 111, 1056-1062.

25. Blomhoff R, Carlsen MH, Andersen LF, et al. (2006) Health benefits of nuts: potential role of antioxidants. BrJ Nutr $\mathbf{9 6}$, S52-S60.

26. Li SC, Liu YH, Liu JF, et al. (2011) Almond consumption improved glycemic control and lipid profiles in patients with type 2 diabetes mellitus. Metab Clin Exp 60, 474-479.

27. Reis CEG, Ribeiro DN, Costa NMB, et al. (2013) Acute and second-meal effects of peanuts on glycaemic response and appetite in obese women with high type 2 diabetes risk: a randomised cross-over clinical trial. Br J Nutr 109, $2015-2023$.

28. Jenkins DJA, Kendall CWC, Marchie A, et al. (2008) Almonds reduce biomarkers of lipid peroxidation in older hyperlipidemic subjects. J Nutr 138, 908-913.

29. Liu JF, Liu YH, Chen CM, et al. (2013) The effect of almonds on inflammation and oxidative stress in Chinese patients with type 2 diabetes mellitus: a randomized crossover controlled feeding trial. Eur J Nutr 52, 927-935.

30. Su XF, Tamimi RM, Collins LC, et al. (2010) Intake of fiber and nuts during adolescence and incidence of proliferative benign breast disease. Cancer Cause Control 21, $1033-1046$

31. Martínez-Lapiscina EH, Clavero P, Toledo E, et al. (2013) Virgin olive oil supplementation and long-term cognition: the PREDIMED-NAVARRA randomized, trial. $J$ Nutr Health Aging 17, 544-552.

32. Varraso R, Kauffmann F, Leynaert B, et al. (2009) Dietary patterns and asthma in the E3N study. Eur Respir J33, 33-41.

33. Maslova E, Granstrom C, Hansen S, et al. (2012) Peanut and tree nut consumption during pregnancy and allergic disease in children - should mothers decrease their intake? Longitudinal evidence from the Danish National Birth Cohort. J Allergy Clin Immunol 130, 724-732.
34. Amre DK, D'Souza S, Morgan K, et al. (2007) Imbalances in dietary consumption of fatty acids, vegetables, and fruits are associated with risk for Crohn's disease in children. Am J Gastroenterol 102, 2016-2025.

35. Pérez-Jiménez J, Neveu V, Vos F, et al. (2010) Identification of the 100 richest dietary sources of polyphenols: an application of the Phenol-Explorer database. Eur J Clin Nutr 64, S112-S120.

36. Bolling BW, Chen YY, Kamil AG, et al. (2012) Assay dilution factors confound measures of total antioxidant capacity in polyphenol-rich juices. $J$ Food Sci 77, H69-H75.

37. Monagas M, Garrido I, Lebron-Aguilar R, et al. (2009) Comparative flavan-3-ol profile and antioxidant capacity of roasted peanut, hazelnut, and almond skins. J Agric Food Chem 57, 10590-10599.

38. Prior RL \& Gu L (2005) Occurrence and biological significance of proanthocyanidins in the American diet. Phytochemistry 66, 2264-2280.

39. Ito H, Okuda T, Fukuda T, et al. (2007) Two novel dicarboxylic acid derivatives and a new dimeric hydrolyzable tannin from walnuts. J Agric Food Chem 55, 672-679.

40. Shahidi F, Alasalvar C \& Liyana-Pathirana CM (2007) Antioxidant phytochemicals in hazelnut kernel (Corylus avellana L.) and hazelnut byproducts. J Agric Food Chem 55, 1212-1220.

41. Chandrasekara N \& Shahidi F (2011) Effect of roasting on phenolic content and antioxidant activities of whole cashew nuts, kernels, and testa. J Agric Food Chem 59, 5006-5014.

42. John JA \& Shahidi F (2010) Phenolic compounds and antioxidant activity of Brazil nut (Bertholletia excelsa). J Funct Food 2, 196-209.

43. Francisco MLD \& Resurreccion AVA (2009) Development of a reversed-phase high performance liquid chromatography (RP-HPLC) procedure for the simultaneous determination of phenolic compounds in peanut skin extracts. Food Chem 117, 356-363.

44. Bolling BW, Dolnikowski G, Blumberg JB, et al. (2009) Quantification of almond skin polyphenols by liquid chromatography-mass spectrometry. J Food Sci 74, C326-C332.

45. Xie L \& Bolling BW (2014) Characterisation of stilbenes in California almonds (Prunus dulcis) by UHPLC-MS. Food Chem 148, 300-306.

46. Wang ML, Chen CY, Tonnis B, et al. (2013) Oil, fatty acid, flavonoid, and resveratrol content variability and FAD2A functional SNP genotypes in the US peanut mini-core collection. J Agric Food Chem 61, 2875-2882.

47. Pellegrini N, Serafini M, Salvatore S, et al. (2006) Total antioxidant capacity of spices, dried fruits, nuts, pulses, cereals and sweets consumed in Italy assessed by three different in vitro assays. Mol Nutr Food Res 50, 1030-1038.

48. Yang J, Liu R \& Halim L (2009) Antioxidant and antiproliferative activities of common edible nut seeds. $L W T$ - Food Sci Technol 42, 1-8.

49. Mandalari G, Tomaino A, Arcoraci T, et al. (2010) Characterization of polyphenols, lipids and dietary fibre from almond skins (Amygdalus communis L.). J Food Comp Anal 23, 166-174.

50. Xie L, Roto AV \& Bolling BW (2012) Characterization of ellagitannins, gallotannins, and bound proanthocyanidins from California almond (Prunus dulcis) varieties. J Agric Food Chem 60, 12151-12156.

51. Liu XD, Villalta PW \& Sturla SJ (2009) Simultaneous determination of inositol and inositol phosphates in complex biological matrices: quantitative ion-exchange 
chromatography/tandem mass spectrometry. Rapid Commun Mass Spectrom 23, 705-712.

52. Colaric M, Veberic R, Solar A, et al. (2005) Phenolic acids, syringaldehyde, and juglone in fruits of different cultivars of Juglans regia L. J Agric Food Chem 53, 6390-6396.

53. Alasalvar C, Amaral JS \& Shahidi F (2006) Functional lipid characteristics of Turkish Tombul hazelnut (Corylus avellana L.). J Agric Food Chem 54, 10177-10183.

54. Li L, Tsao R, Yang R, et al. (2007) Fatty acid profiles, tocopherol contents, and antioxidant activities of heartnut (Juglans ailanthifolia Var. cordiformis) and Persian Walnut (Juglans regia L.). I Agric Food Chem 55 , $1164-1169$

55. Toschi TG, Caboni MF, Penazzi G, et al. (1993) A study on cashew nut oil composition. J Am Oil Chem Soc 70, 1017-1020.

56. Jonnala RS, Dunford NT \& Dashiell KE (2006) Tocopherol, phytosterol and phospholipid composition of new high oleic peanut cultivars. J Food Comp Anal 19, 601-605.

57. Barreira JCM, Alves RC, Casal S, et al. (2009) Vitamin E profile as a reliable authenticity discrimination factor between chestnut (Castanea sativa Mill.). I Agric Food Chem 57, 5524-5528.

58. Wall MM (2010) Functional lipid characteristics, oxidative stability, and antioxidant activity of macadamia nut (Macadamia integrifolia) cultivars. Food Chem 121, 1103-1108.

59. Shin E-C, Huang Y-Z, Pegg R, et al. (2009) Commercial runner peanut cultivars in the United States: tocopherol composition. J Agric Food Chem 57, 10289-10295.

60. Bada JC, León-Camacho M, Prieto M, et al. (2010) Characterization of walnut oils (Juglans regia L.) from Asturias, Spain. J Am Oil Chem Soc 87, 1469-1474.

61. Gómez-Caravaca AN, Verardo V \& Caboni MF (2010) Chromatographic techniques for the determination of alkyl-phenols, tocopherols and other minor polar compounds in raw and roasted cold pressed cashew nut oils. J Chromatogr A 1217, 7411-7417.

62. Trumbo P, Schlicker S, Yates A, et al. (2002) Dietary reference intakes for energy, carbohydrate, fiber, fat, fatty acids, cholesterol, protein and amino acids. J Am Diet Assoc 102, 1621-1630.

63. Kris-Etherton PM, Hu FP, Ros E, et al. (2008) The role of tree nuts and peanuts in the prevention of coronary heart disease: multiple potential mechanisms. J Nutr 138, S1746-S1751.

64. Kaijser A, Dutta P \& Savage G (2000) Oxidative stability and lipid composition of macadamia nuts grown in New Zealand. Food Chem 71, 67-70.

65. Nórmen L, Ellegård L, Brants H, et al. (2007) A phytosterol database: fatty foods consumed in Sweden and the Netherlands. J Food Comp Anal 20, 193-201.

66. Crews C, Hough P, Godward J, et al. (2005) Study of the main constituents of some authentic walnut oils. J Agric Food Chem 53, 4853-4860.

67. Alasalvar C, Amaral JS, Satır G, et al. (2009) Lipid characteristics and essential minerals of native Turkish hazelnut varieties (Corylus avellana L.). Food Chem 113, 919-925.

68. Yorulmaz A, Velioglu YS, Tekin A, et al. (2009) Phytosterols in 17 Turkish hazelnut (Corylus avellana L.) cultivars. Eur J Lipid Sci Technol 111, 402-408.

69. Shin E-C, Pegg RB, Phillips RD, et al. (2010) Commercial peanut (Arachis bypogaea L.) cultivars in the United States: phytosterol composition. J Agric Food Chem 58, 9137-9146.

70. Yousfi M, Nedjmi B, Bellal R, et al. (2002) Letters to editor fatty acids and sterols of Pistacia atlantica fruit oil. J Am Oil Chem Soc 79, 1049-1051.
71. da Costa PA, Ballus CA, Teixeria-Filho J, et al. (2010) Phytosterols and tocopherols content of pulp and nuts of Brazilian fruits. Food Rev Int 43, 1603-1606.

72. Wang Y, Tan D \& Ho C-T (2009) Sphingolipids in tree nuts. In Tree Nuts: Composition, Phytochemicals, and Health Effects, pp. 85-93 [C Alasalvar and F Shahidi, editors]. Boca Raton, FL: CRC Press, Taylor \& Francis Group.

73. Miraliakbari $\mathrm{H} \&$ Shahidi F (2008) Antioxidant activity and minor components of tree nut oils. Food Chem 111, 421-427.

74. Miraliakbari H \& Shahidi F (2008) Oxidative stability of tree nut oils. J Agric Food Chem 56, 4751-4759.

75. Kornsteiner M, Wagner K-H \& Elmadfa I (2006) Tocopherols and total phenolics in 10 different nut types. Food Chem 98, 381-387.

76. Bellomo MG \& Fallico B (2007) Anthocyanins, chlorophylls and xanthophylls in pistachio nuts (Pistacia vera) of different geographic origin. J Food Comp Anal 20, 352-359.

77. Trox J, Vadivel V, Vetter W, et al. (2010) Bioactive compounds in cashew nut (Anacardium occidentale L.) kernels: effect of different shelling methods. J Agric Food Chem 58, 5341-5346.

78. Bouali I, Trabelsi H, Abdallah IB, et al. (2013) Changes in fatty acid, tocopherol and xanthophyll contents during the development of Tunisian-grown pecan nuts. J Am Oil Chem Soc 90, 1869-1876.

79. Cheikh-Rouhou S, Hentati B, Besbes S, et al. (2006) Chemical composition and lipid fraction characteristics of Aleppo pine (Pinus halepensis Mill.) seeds cultivated in Tunisia. Food Sci Technol Int 15, 407-416.

80. Trevisan M, Pfundstein B, Haubner R, et al. (2006) Characterization of alkyl phenols in cashew (Anacardium occidentale) products and assay of their antioxidant capacity. Food Chem Toxicol 44, 188-197.

81. Saitta M, Giuffrida D, La Torre GL, et al. (2009) Characterisation of alkylphenols in pistachio (Pistacia vera L.) kernels. Food Chem 117, 451-455.

82. Kubo I, Komatsu S \& Ochi M (1986) Molluscicides from cashew Anacardium occidentale and their large-scale isolation. J Agric Food Chem 34, 970-973.

83. Sathe SK, Monaghan EK, Kshirsagar HH, et al. (2009) Chemical composition of edible nut seeds and its implications in human health. In Tree Nuts: Composition, Phytochemicals, and Health Effects, pp. 11-35 [C Alasalvar and F Shahidi, editors]. Boca Raton, FL: CRC Press, Taylor \& Francis Group.

84. Food and Drug Administration (2003) Qualified Health Claims: Letter of Enforcement Discretion - Nuts and Coronary Heart Disease (Docket No. 02P-0505). Washington, DC: Food and Drug Administration.

85. Lui RH (2003) Health benefits of fruits and vegetables are from additive and synergistic combinations of phytochemicals. Am J Clin Nutr 78, S517-S520.

86. Thompson HJ, Heimendinger J, Dicker A, et al. (2006) Dietary botanical diversity affects the reduction of oxidative biomarkers in women due to high vegetable and fruit intake. J Nutr 136, 2207-2212.

87. He X \& Liu RH (2008) Phytochemicals of apple peels: isolation, structure elucidation, and their antiproliferative and antioxidant activities. J Agric Food Chem 56, 9905-9910.

88. Yang J, Martinson TE \& Liu RH (2009) Phytochemical profiles and antioxidant activities of wine grapes. Food Chem 116, 332-339.

89. Vinson JA \& Cai Y (2012) Nuts, especially walnuts, have both antioxidant quantity and efficacy and exhibit significance potential health benefits. Food Funct 3, 134-140. 
90. Halvorsen BL, Holte K, Myhrstad MCW, et al. (2002) A systematic screening of total antioxidants in dietary plants. J Nutr 132, 461-471.

91. Arcan I \& Yemenicioğlu A (2009) Antioxidant activity and phenolic content of fresh and dry nuts with or without seed coat. J Food Comp Anal 22, 184-188.

92. Abe LT, Lajolo M \& Genovese MI (2010) Comparison of phenol content and antioxidant capacity of nuts. Ciênc Technol Aliment Campinas 30, 254-259.

93. Casas-Agustench P, Salas-Huetos A \& Salas-Salvado J (2011) Mediterranean nuts: origins, ancient medicinal benefits and symbolism. Public Health Nutr 14, 2296-2301.

94. Food and Drug Administration (2004) Qualified Health Claims: Letter of Enforcement Discretion - Walnut and Coronary Heart Disease (Docket No. 02P-0292). Washington, DC: Food and Drug Administration.

95. EFSA Panel on Dietetic Products, Nutrition and Allergies (NDA) (2011) Scientific opinion on the substantiation of health claims related to walnuts and maintenance of normal blood LDL-cholesterol concentrations (ID 1156, 1158) and improvement of endothelium-dependent vasodilation (ID 1155, 1157) pursuant to Article 13(1) of Regulation (EC) no. 1924/2006. EFSA J 9, 2074.

96. Bao Y, Han JL, Hu FB, et al. (2013) Association of nut consumption with total and cause-specific mortality. $N$ Engl J Med 369, 2001-2011.

97. Gopinath B, Buyken AE, Flood VM, et al. (2011) Consumption of polyunsaturated fatty acids, fish, and nuts and risk of inflammatory disease mortality. Am J Clin Nutr 93, $1073-1079$.

98. Estruch R, Ros E, Salas-Salvadó J, et al. (2013) Primary prevention of cardiovascular disease with a Mediterranean diet. $N$ Engl J Med 368, 1279-1290.

99. Guasch-Ferré M, Bulló M, Martínez-González MA, et al. (2013) Frequency of nut consumption and mortality risk in the PREDIMED nutrition intervention trial. BMC Med 11, 164 .

100. Nergiz-Unal R, Kuijpers MJE, de Witt SM, et al. (2013) Atheroprotective effect of dietary walnut intake in ApoEdeficient mice: involvement of lipids and coagulation factors. Thromb Res 131, 411-417.

101. Berryman CE, Grieger JA, West SG, et al. (2013) Acute consumption of walnuts and walnut components differentially affect postprandial lipemia, endothelial function, oxidative stress, and cholesterol efflux in humans with mild hypercholesterolemia. J Nutr 143, 788-794.
102. Tsujita T, Yamada M, Takaku T, et al. (2011) Purification and characterization of polyphenols from chestnut astringent skin. J Agric Food Chem 59, 8646-8654.

103. Tsujita T, Shintani T \& Sato H (2013) Alpha-amylase inhibitory activity from nut seed skin polyphenols. 1. Purification and characterization of almond seed skin polyphenols. J Agric Food Chem 61, 4570-4576.

104. Rothwell JA, Urpi-Sarda M, Boto-Ordoñez M, et al. (2012) Phenol-Explorer 2.0: a major update of the Phenol-Explorer database integrating data on polyphenol metabolism and pharmacokinetics in humans and experimental animals. Database 2012, bas031.

105. US Department of Agriculture (2013) USDA database for the flavonoid content of selected foods, release 3.1. http://www.ars.usda.gov/nutrientdata/flav (accessed January 2014).

106. Otles S \& Selek I (2012) Phenolic compounds and antioxidant activities of chestnut (Castanea sativa Mill.) fruits. Qual Assur Safety Crop Food 4, 199-205.

107. Pelvan E, Alasalvar C \& Uzman S (2012) Effects of roasting on the antioxidant status and phenolic profiles of commercial Turkish hazelnut varieties (Corylus avellana L.). J Agric Food Chem 60, 1218-1223.

108. Li L, Tsao R \& Yang R (2006) Polyphenolic profiles and antioxidant activities of heartnut (Juglans ailanthifolia var. cordiformis) and Persian walnut (Juglans regia L.). J Agric Food Chem 54, 8033-8040.

109. de la Rosa LA, Alvarez-Parrilla E \& Shahidi F (2011) Phenolic compounds and antioxidant activity of kernels and shells of Mexican pecan (Carya illinoinensis). J Agric Food Chem 59, 152-162.

110. Mandalari G, Bisignano C, Filocamo A, et al. (2013) Bioaccessibility of pistachio polyphenols, xanthophylls, and tocopherols during simulated human digestion. Nutrition 29, 338-344.

111. Gómez-Caravaca AM, Verardo V, Segura-Carretero A, et al. (2008) Development of a rapid method to determine phenolic and other polar compounds in walnut by capillary electrophoresis-electrospray ionization time-of-flight mass spectrometry. J Chromatogr A 1209, 238-245.

112. Zlatanov MD, Antova GA, Angelova-Romova MJ, et al. (2013) Lipid composition of Castanea sativa Mill. and Aesculus hippocastanum fruit oils. I Sci Food Agric 93, 661-666.

,

